\title{
A FOCUSED EDUCATIONAL PROGRAM FOR FRONT-LINE HEALTH CARE WORKERS DURING COVID -19 OUTBREAK IMPROVES MENTAL HEALTH
}

\author{
Urwah Ikhlaq, Madiha Umair, Komal Baloch, Imran Ansari, Jawed Abu Baker, Nawal Salahuddin
}

National Institute of Cardiovascular Diseases, Karachi Pakistan

\begin{abstract}
Objective: To determine whether an educational program on personal protective measures can reduce anxiety and depression in Hospital workers exposed to COVID-19.

Study Design: Quasi-experimental study.

Place and Duration of Study: COVID Units \& Emergency Room, from May to Jul 2020.

Methodology: Educational tool based on World Health Organization and Pan American Health Organization guidelines including videos on Personal Protective Equipment usage was delivered to hospital staff assigned to areas with COVID-19 patients. Likert scale, Generalised Anxiety Disorder-7 score and Major Depression Inventory were used.

Results: 100 hospital staff were included. About $40 \%$ doctors, $41 \%$ Nurses. None had preexisting anxiety or depression. About $11 \%$ reported COVID-19, 46\% reported quarantine, and 91\% reported contact. About 93\% stated insufficient knowledge of usage of personal protective equipment and $35 \%$ reported inadequate provision of personal protective equipment. Median score on the likert scale was 5 (IQR 4-7). Mean generalized anxiety disorder score was $6.48 \pm 3.4$, which improved to $4.65 \pm$ 2.7 post session, $p$-value $<0.001$. $41 \%$ reported minimal, $34 \%$ mild, $24 \%$ moderate and $1 \%$ severe anxiety. Post session, $62 \%$ reported minimal Anxiety, 33\% mild, 5\% moderate and 0\% severe anxiety. Mean major depression inventory score was $16.10 \pm$ 7.05 which reduced to $13.58 \pm 5.84, p$-value $<0.001$. Presession $59 \%$ reported 'no/doubtful depression', $40 \%$ mild, $1 \%$ moderate depress-sion, while post-session $85 \%$ reported 'no/doubtful', 15\% mild and none had moderate/severe depression.

Conclusion: We found an educational program that provided information on personal protective measures significantly reduced anxiety and depression in front-line workers during COVID-19 pandemic.
\end{abstract}

Keywords: Anxiety, COVID-19, Depression, Health care workers, Personal protective equipment.

How to Cite This Article: Ikhlaq U, Umair M, Baloch K, Ansari I, Baker JA, Salahuddin N. A Focused Educational Program for Front-Line Health Care Workers During COVID-19 Outbreak Improves Mental Health. Pak Armed Forces Med J 2021; 71(5): 1870-1874. _ doi: https://doi.org/10.51253/pafmj.v71i5.5541

This is an Open Access article distributed under the terms of the Creative Commons Attribution License (https://creativecommons.org/licenses/by-nc/4.0/), which permits unrestricted use, distribution, and reproduction in any medium, provided the original work is properly cited.

\section{INTRODUCTION}

COVID-19, an emerging disease creating havoc all around the globe is caused by the newly discovered Corona virus SARS CoV-2, which was first identified in Wuhan, China in Dec 2019. Since then and till date (as of $16^{\text {th }}$ Oct 2020), the notorious virus has affected around 216 countries, infecting about 9,277,214 people and leading to 478,691 number of fatalities along with worldwide economic recession and psychological devastation. ${ }^{1}$ Lockdown restrictions, mass quarantine and social distancing accompanied with fears of contagion, illness and death have all led to an epidemic of depression and anxiety across the world.

This is specifically relevant to frontline healthcare workers who are at the highest risks of stress stemming from fears of infection, social isolation with reduced contact with family and physical and mental exhaustion. Most stress related to SARS CoV-2 originates from uncertainty about methods of protection against

Correspondence: Dr Urwah Ikhlaq, Department of Medicine, National Institute of Cardiovascular Disease, Karachi, Rawalpindi Pakistan

Received: 29 Dec 2020; revision received: 01 Feb 2021; accepted: 10 Feb 2021 the virus whilst involved in direct care of patients with COVID. Availability of Personal Protective Equipment (PPE) and its safe usage methods, the 'donning' and 'doffing' are therefore important. A previous study reported mental stress in Frontline workers caring for COVID-19 patientsin Wuhan. The results showed depression in $50.4 \%$ while anxiety in $44.6 \%$, insomnia in $34 \%$ respondents and distress in $71 \% .^{2}$ Another similar study highlighted that hospital workers other than those concerned with direct patient care, were at highest risk for mental distress and interventions aiming to help this vulnerable group was needed. ${ }^{3}$

Chinese investigators, ${ }^{4}$ reported moderate to severe stress in frontline health care workers in Wuhan where one in five had elevated anxiety and one in ten exhibited depression. HCWs who had better knowledge about COVID-19 performed better during the emergency response. Therefore addressing mental health concerns is highly important to control the pandemic. ${ }^{5}$ In fact, a recent editorial has called for providing guidance and stressing on psychological interventions for HCWs. ${ }^{6}$ 
Validated general screening instruments to measure the psychological state of personnel include depression, anxiety and stress scale (DASS), hamilton anxiety scale (HAMA), hamilton depression score (HAMD), generalized anxiety disorder GAD 7 score, major depressive inventory (MDI), impact of events scale-revised (IES-R). COVID-19 specific scales have also been developed, namely; COVID-19 stress scale (CSS), perceived stress scale modified for COVID-19 (PSS-10-C), COVID-19 peri-traumatic distress index (CPDI), COVID-19 related psychological distress in healthy public (CORPD), anxiety of COVID scale (CAS), fear of COVID-19 scale (FC-19 S), obsession with COVID-19 scale (OCS), COVID-19 phobia scale (C19 PS), post COVID-19 functional status scale (PCFS). ${ }^{7}$ Investigators in a study from Singapore examined psychological distress, depression, anxiety, and stress experienced by health care workers in the midst of the COVID-19 outbreak using DASS-21 and IES-R, ${ }^{8}$ while GAD 7 scoring was used to assess the level of anxiety among doctors during COVID-19 pandemic and the associated risk factors. ${ }^{9}$

Insufficient knowledge of and access to personal protective equipment leads to stress and anxiety amongst healthcare workers which can possibly be minimized by educating them about necessary steps of Donning and Doffing and by answering to their queries regarding COVID-19.

\section{METHODOLOGY}

We carried out a quasi-experimental study from May to July 2020. The study design was approved by the institutional Research Ethics Committee (ERC approval reference number: ERC-17/2020). Informed consent to participate and publish was obtained. The study has been performed in accordance with the ethics standards laid down in the 1964 Declaration of Helsinki and its later amendments.

Inclusion Criteria: Adult hospital workers working in units with exposure to COVID-19 patients were included. These included doctors, nurses, technicians, housekeeping staff, unit receptionists.

Exclusion Criteria: Those with a history of a prior major depression or an anxiety disorder were excluded.

Results of a study conducted by Lai et al, ${ }^{2}$ showed depression in $50.4 \%$ while anxiety in $44.6 \%$ among hea1th care workers exposed to COVID-19, taking $44.6 \%$ as prevalence guess, at $95 \%$ confidence level, and $10 \%$ margin of error, sample size of $\mathrm{n}=95$ was calculated, however, a total of 100 hospital workers were recruited for this study. Non-probability consecutive sampling technique was used.

Hospital workers were asked to fill out a validated questionnaire that included questions on concerns about COVID-19. They were then assessed for awareness about the disease using the likert scale followed by an evaluation of mental healthiness with validated tools; Generalized Anxiety Disorder GAD-7 score and Major depressive Inventory (MDI).

Anxiety was assessed using the GAD-7 (Generalized Anxiety), ${ }^{10-12}$ Score that rapidly screens for the presence of a clinically significant anxiety disorder and objectively determines symptom change over time. The scoring was done by questions that inquired about symptoms of anxiety, severity of which was assessed by Likert scale 0 to 3 with 0 referring to having symptoms 'not at all', 1 for symptoms 'less than half of the days', 2 for symptoms 'more than half the days' and 3 for symptoms 'nearly every day'. The sum of scores indicated the level of anxiety, grading it to level 'minimal' if score was between 0-4, 'mild' if score was 5-9, 'moderate' with score of 10-14 and 'severe' with score 15-21. The Urdu translated version of GAD 7 that is already validated, ${ }^{13}$ was used wherever needed.

Depression was assessed by the Major Depression Inventory (MDI score), ${ }^{14,15}$ which screens for and can help objectify and rate the severity of depression. Major Depressive Inventory Scoring includes 10 items questioning about symptoms regarding depression. Each is scored on a Likert scale 0 to 5 , with 0 score referring to 'at no time' and 5 referring to 'at all times'. For items $8 \mathrm{a}$ vs. $8 \mathrm{~b}$ and $10 \mathrm{a}$ vs. $10 \mathrm{~b}$, the highest score on $\mathrm{a}$ or $\mathrm{b}$ is used. The ten items were then summed up to give a total score for Depression severity 0-5 standardized as 'No or doubtful depression' when total score was between $0-20$, 'mild' with score of 21-25, 'moderate' when between 26-30 and 'severe' when between 31-50. These MDI questions were translated in general Urdu terms easily understandable and applicable to the general public.

An educational session on standard personal protective measures was conducted in a lecture format that included a multimedia presentation with reference to guidelines formed by WHO (World Health Organization) and PAHO (Pan American Health Organization). ${ }^{16,17}$ 
Standard operating procedures were followed during the educational sessions to ensure appropriate social distancing. The sessions included hands on teaching of appropriate Donning and Doffing technique of PPE and the staff was provided opportunities for a question and answer session.

After the educational session, the participants were again evaluated using the MDI and GAD 7 instruments. This was not done immediately but at 2-4 weeks later.

Continuous data is reported as means with standard deviation or medians with IQR. Categorical data is reported as proportions. Chi square test or Student t-test for paired samples were used to compare preeducational and post-educational session variables. The $p$-value of $\leq 0.05$ was considered as statistically significant. All data was analyzed using Statistical Package for Social Sciences version 22.

\section{RESULTS}

A total of 100 hospital staff assigned to COVID Unit, Emergency Room, Surgical areas (including Surgical ICU and Operating Theatre), Cardiology Units (ICU and Cath Lab) were surveyed. About 100 percent of respondents were routinely dealing with COVID-19 patients. Distribution of respondents is shown in Figure-1.

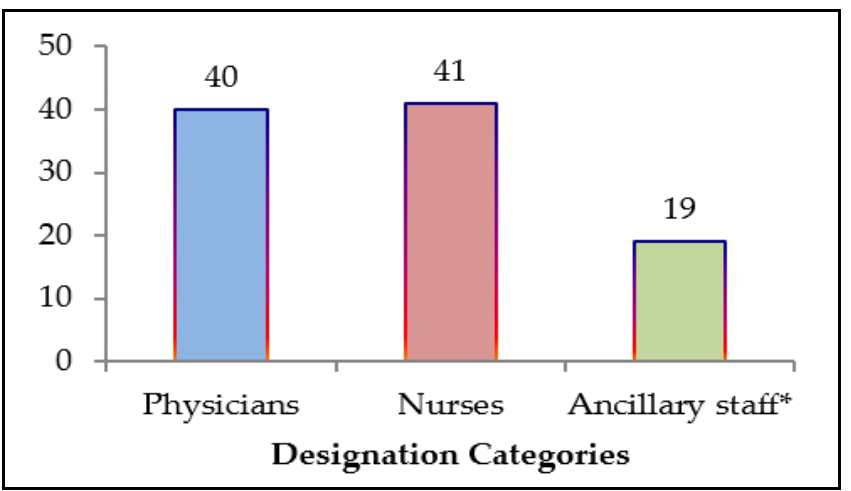

*Includes Housekeeping, Porters, Technicians

Figure: Distribution of respondents.

About $71 \%$ were male. Zero percent respondents had preexisting anxiety or depression on screening. About 9\% had previous experience of dealing with public health emergencies. Regarding COVID-19, 71\% felt they had adequate knowledge at time of survey on the Knowledge likert scale; median score was 5 (IQR 47) (Figure-2).

About $11 \%$ had been previously infected and $46 \%$ had been quarantined for exposure, $74 \%$ reported an infected colleague and $17 \%$ reported an infected family

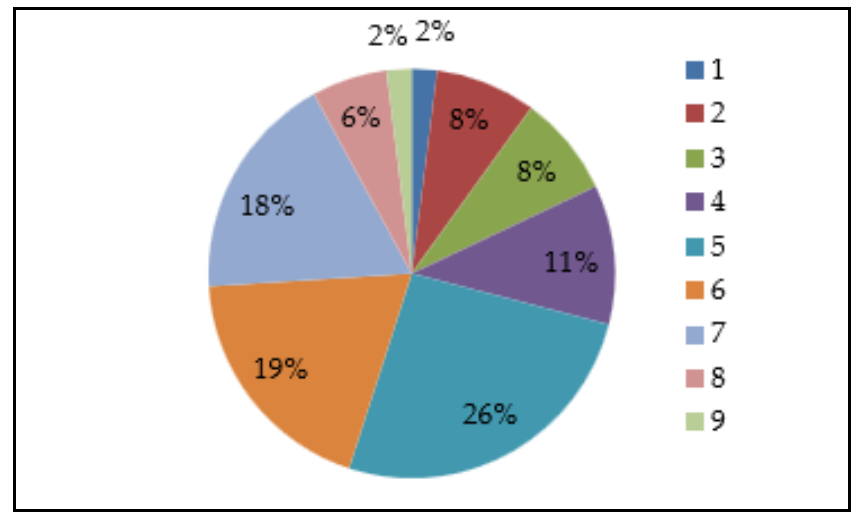

Figure-2: Distribution of knowledge responses on Likert scale.

member. 33\% reported 'fear of death' if they acquired infection and 100 percent worried about transmitting infection to their loved ones. Regarding Use of PPE, 35 percent reported inadequate provision of PPE in their unit and 93 admitted having insufficient knowledge of use of PPE.

A significant decline in the post session mean GAD score was observed $(p<0.001)$ with mean difference of 1.83 (95\% CI: 1.48-2.17). Post-session categorization of GAD score showed significant improvement in severity of anxiety, significant decline in postsession mean MDI score was observed $(p<0.001)$ with mean difference of 2.52 (95\% CI: 2.0-3.02). Post-session categorization of MDI score showed significant improvement in severity of depression, as shown in the Table.

Table: Comparison pre and post session generalized anxiety disorder and major depression inventory results.

\begin{tabular}{|c|c|c|c|}
\hline & \multicolumn{2}{|c|}{ Phase } & \multirow{2}{*}{$\begin{array}{c}p- \\
\text { value }\end{array}$} \\
\hline & Pre-Session & Post-Session & \\
\hline $\begin{array}{l}\text { Generalized } \\
\text { Anxiety Disorder }\end{array}$ & $6.48 \pm 3.44$ & $4.65 \pm 2.76$ & $<0.001$ \\
\hline Minimal & $41(41 \%)$ & $62(62 \%)$ & \multirow{4}{*}{$<0.001$} \\
\hline Mild & $34(34 \%)$ & $33(33 \%)$ & \\
\hline Moderate & $24(24 \%)$ & $5(5 \%)$ & \\
\hline Severe & $1(1 \%)$ & - & \\
\hline $\begin{array}{l}\text { Major Depression } \\
\text { Inventory }\end{array}$ & $16.1 \pm 7.06$ & $13.58 \pm 5.84$ & $<0.001$ \\
\hline $\begin{array}{l}\text { No or doubtful } \\
\text { depression }\end{array}$ & $59(59 \%)$ & $85(85 \%)$ & \multirow{3}{*}{$<0.001$} \\
\hline Mild depression & $40(40 \%)$ & $15(15 \%)$ & \\
\hline $\begin{array}{l}\text { Moderate } \\
\text { depression }\end{array}$ & $1(1 \%)$ & - & \\
\hline
\end{tabular}

\section{DISCUSSION}

We found that a significant number of frontline HCWs were stressed because of insufficient knowledge of the usage of and access to PPE. An educatio- 
nal program oriented to PPE usage and dispelling myths about COVID-19, significantly decreased anxiety levels amongst the participants. Similarly, the MDI scoring assessment showed that after the educational session, a significant proportion showed an appreciable change in the grade of depression.

Ruotsalainen et al, ${ }^{18}$ reviewed 58 RCTs from the Cochrane Data Base that reviewed the effectiveness of organization-directed and person-directed interventions in preventing work-place stress in health care workers. They found that person-directed interventions (Cognitive Behavioral Therapy, meditation, massage are as useful as organization-directed interventions (change of working conditions and schedule, increasing communication skills, support). For this reason, in our study, we developed an educational program to relieve stress in hospital personnel.

With relevance to COVID-19 and reducing mental stress of healthcare workers, of out 59 studies, only 6 used an intervention. ${ }^{19}$ Sometargeted organizational adjustments, some facilitated collegial support, and some were addressing individual complaints or strategies of quarantining, establishing telephone-based hotlines for psychological support of HCWs and guidance on personal protective equipment. Hong et $a l,{ }^{20}$ reported on a "comprehensive psychological intervention" for healthcare workers directly exposed to COVID-19. This involved an adjustment in shift work with a 2-week work schedule followed by a 2-week quarantine. Chen et al,,11 reported on the results of a telephone-based support system. However, healthcare workers reported needing personal protective equipment and rest, not time with a psychologist. Schulte et al. ${ }^{22}$ developed a video system to provide targeted individual professional support. Chung and Yeung, ${ }^{23}$ also developed an online questionnaire targeting psychological support whilst Jiang et al. ${ }^{24}$ described one-onone "psychological crisis intervention" for healthcare workers.

Unfortunately, none of these studies assessed the effects of their interventions. ${ }^{19}$ In our study, we not only developed an educational program targeting needs identified by previous reports, but we also assessed the mental health of our respondents both before and after the intervention.

In a qualitative inquiry by Munawwar et al,25,15 HCWs directly dealing with COVID-19 patients were interviewed. They found that healthcare workers practiced, and even recommended to others, strategies to cope up with mental stress which included limiting media exposure, limiting sharing of COVID duty details with other colleagues, using religious beliefs to help with coping, and focusing on altruism and empathy for patients and their families and passion to support resilience amongst health care workers. Based on their results, our educational program was designed to be delivered by colleagues working at the same unit and was culturally appropriate.

A major strength of our study is that we included all hospital workers, both medical personnel and nonmedical personnel, with improved mental health seen in both groups after the educational intervention. In addition, though other investigators have focused on mental health issues, we have not been able to find any other reports of specific assessments of the impact of an intervention that aimed to improve mental health in HCWs exposed to COVID-19.

\section{LIMITATIONS OF STUDY}

A possible limitation of our study was that not all 100 participants could be assessed together at the same educational session due to precautions taken to implement SOPs to prevent COVID-19 spread amongst the participants. Sessions were conducted at different times and the post-session evaluation was done at 2 weeks for some and at 4 weeks' for others instead of all being done specifically at 2 weeks.

\section{CONCLUSION}

We found that an educational program providing information on personal protective measures significantly reduced anxiety and depression in front-line workers during COVID -19 pandemic.

\section{Conflict of Interest: None.}

\section{Authors' Contribution}

UI: Conception, design, drafting, MU: Conception, design, review, KB: Design, drafting, data acquisition, IA: Drafting, data acquisition, JAB: Conception, supervision and interpretation, NS: Conception, supervision \& interpretation.

\section{REFERENCES}

1. Worldometer. Reported Cases and Deaths by Country, Territory 2020, [Internet] Available from: https://www. worldometers info/coronavirus/?fbclid=IwAR3qSM_h4JZq4zKIarVnjsmxeJdE 3LU8AqwztYpG5zR9AtTj5vs2AGvraaQ\#countries [Accessed on : October16, 2020].

2. Lai J, Ma S, Wang Y, Cai Z, Hu J, Wei N, et al. Factors Associated With Mental Health Outcomes Among Health Care Workers Exposed to Coronavirus Disease 2019. JAMA Netw Open 2020; 3(3): e203976.

3. Tan BYQ, Chew NWS, Lee GKH, Jing M, Goh Y, Yeo LLL, et al Psychological Impact of the COVID-19 Pandemic on Health Care Workers in Singapore. Ann Intern Med 2020; 173(4): 317-320.

4. Du J, Dong L, Wang T, Yuan C, Fu R, Zhang L, et al. Psychological symptoms among frontline healthcare workers during COVID-19 outbreak in Wuhan. Gen Hosp Psychiatry 2020; 67(2): 144-145. 
5. Banerjee D. The COVID-19 outbreak: Crucial role the psychiatrists can play. Asian J Psy 2020; 50(2): 102014.

6. Rana W, Mukhtar S, Mukhtar S. Mental health of medical workers in Pakistan during the pandemic COVID-19 outbreak. Asian J Psych 2020; 51(1): 102080.

7. Cortez PA, Joseph SJ, Das N, Bhandari SS, Shoib S. Tools to measure the psychological impact of the COVID-19 pandemic: What do we have in the platter?. Asian J Psy 2020; 53(2): 102371.

8. Tan BY, Chew NW, Lee GK, Jing M, Goh Y, Yeo LL, et al. Psychological Impact of the COVID-19 pandemic on health care workers in Singapore. Ann Intern Med 2020; 173(4): 317-20.

9. Hasan SR, Hamid Z, Jawaid MT, Ali RK. Anxiety among Doctors during COVID-19 Pandemic in Secondary and Tertiary Care Hospitals. Pak J Med Sci 2020; 36(6): 1360-1365.

10. Spitzer RL, Kroenke K, Williams JBW, Löwe B. A brief measure for assessing generalized anxiety disorder: The GAD-7. Arch Intern Med 2006; 166(10): 1092-1097.

11. Ruiz MA, Zamorano E, García-Campayo J, Pardo A, Freire O, Rejas J. Validity of the GAD-7 scale as an outcome measure of disability in patients with generalized anxiety disorders in primary care. J Affect Disord 2011; 128(3): 277-286.

12. Kroenke K, Spitzer RL, Williams JB, Monahan PO, Löwe B. Anxiety disorders in primary care: prevalence, impairment, comorbidity, and detection. Ann Intern Med 2007; 146(5): 317325.

13. Ahmad S, Hussain S, Shah FS, Akhtar F. Urdu translation and validation of GAD-7: A screening and rating tool for anxiety symptoms in primary health care. J Pak Med Assoc 2017; 67(10): 1536-1540.

14. Bech P, Rasmussen NA, Olsen LR, Noerholm V, Abildgaard W. The sensitivity and specificity of the major depression inventory, using the present state examination as the index of diagnostic validity. J Affect Disord 2001; 66(2-3): 159-164.

15. Olsen LR, Jensen DV, Noerholm V, Martiny K, Bech P. The internal and external validity of the major depression inventory in measuring severity of depressive states. Psychol Med 2003; 33(2): 351-356.
16. PAHO. Video-Donning of personal protective equipment (PPE) 2020, [Internet] Available from: https://www.paho.org/en/ news/17-6-2020-video-donning-personal-protec-tiveequipmentppe [Accessed on October 27, 2020].

17. PAHO. Presentation: infection prevention and control and novel coronavirus (COVID-19): standard precautions and use of personal protective equipment 2020, [Internet] Available from: https://www.paho.org/en/documents/ presentation-infectionprevention-and-control-and-novel-coronavirus-covid-19standard [Accessed on October 27, 2020].

18. Ruotsalainen JH, Verbeek JH, Mariné A, Serra C. Preventing occupational stress in healthcare workers. Cochrane Database Syst Rev 2015; 2015(4): CD002892.

19. Muller AE, Hafstad EV, Himmels JPW, Smedslund G, Flottorp S, Stensland S, et al. The mental health impact of the COVID-19 pandemic on healthcare workers, and interventions to help them: A rapid systematic review. Psychiatry Res 2020; 293(2): 113441.

20. Hong X, Cao J, Wei J, Duan Y, Zhao X, Jing J, et al. the stress and psychological impact of the COVID-19 outbreak on medical workers at the fever clinic of a tertiary general hospital in beijing: a cross-sectional study. [PREPRINT] Available at: http:// dx.doi.org/10.2139/ssrn.3566244 [Accessed on October 27, 2020].

21. Chen Q, Liang M, Li Y, Guo J, Fei D, Wang L, et al. Mental health care for medical staff in China during the COVID-19 outbreak. Lancet Psy 2020; 7(4): e15-e16.

22. Schulte EE, Bernstein CA, Cabana MD. Addressing faculty emotional responses during the coronavirus 2019 pandemic. J Pediat 2020; 222(1): 13-14.

23. Liu S, Yang L, Zhang C, Xiang YT, Liu Z, Hu S, et al. Online mental health services in China during the COVID-19 outbreak. Lancet Psy 2020; 7(4): e17-e18.

24. Jiang X, Deng L, Zhu Y, Ji H, Tao L, Liu L, et al. Psychological crisis intervention during the outbreak period of new coronavirus pneumonia from experience in Shanghai. Psy Res 2020; 286(2): 112903.

25. Munawar K. Exploring stress coping strategies of frontline emergency health workers dealing COVID-19 in Pakistan: A qualitative inquiry. Am J Infect Control 2021; 49(3): 286-292. 